\title{
A survey on the impact of COVID-19 on incomes and practice patterns of private-sector physicians in Singapore
}

\section{Dear Editor,}

The effects of COVID-19 have impacted the Singapore economy, including the healthcare sector. ${ }^{1,2}$ The Singapore healthcare system is broadly split into public and private sectors. While there have been no documented salary cuts affecting public-sector workers, anecdotal evidence suggests that the incomes of privatesector physicians have been affected adversely by COVID-19. Quantitative data in this area are lacking.

The Singapore Medical Association (SMA), as the national medical association of Singapore, commissioned a descriptive study to evaluate the impact of COVID-19 on incomes and practice patterns of medical practitioners in the private sector. The study will allow the medical profession to better understand and cope with future pandemics.

SMA represents the interests of a majority of medical practitioners in the public and private healthcare sectors. It has 6,025 members who are registered practitioners, and maintains a database of members' email addresses. An online survey assessing the impact of the COVID-19 pandemic on private-sector physicians was commissioned and conducted from 15 May to 31 May 2020. The survey was hosted using SurveyMonkey online survey software. Two email blasts were sent to invite SMA members to participate in the survey, and it was advised that only private-sector practitioners should respond to the survey. As this was an anonymised, commissioned survey that did not involve any patients, institutional review board approval was not required. The SMA Council reviewed and approved the survey.

The current study adopted a semi-qualitative approach, wherein quantitative data collected were described qualitatively. Of the 2,498 private-sector SMA members who were sent the email, 1,184 respondents participated in the survey but only 902 completed it. They comprised 394 (43.7\%) specialist doctors and $508(56.3 \%)$ general practitioners (GPs).

Monthly income. There were $702(77.8 \%)$ respondents who reported a monthly income loss of $>50 \%$, and $407(45.1 \%)$ reporting a loss of $>75 \%$ (Table 1$)$. After factoring in government-related assistance, the percentage of respondents reporting income losses of $>50 \%$ and $>75 \%$ fell from $77.8 \%$ to $72.7 \%(5.1 \%$ improvement), and $45.1 \%$ to $38.2 \%$ (6.9\% improvement), respectively. There were $47(5.2 \%)$ physicians who reported no income. This was lowered to 44 (4.9\%) after relief measures.

Specialists' monthly incomes were more affected than GP incomes. For income losses of $>50 \%, 82.5 \%$ of specialists surveyed were affected, compared to $74.2 \%$ of GPs surveyed. For income losses of $>75 \%, 52 \%$ of specialists and $39.8 \%$ of GPs surveyed were affected. Relief measures were more significant for GPs than specialists. After government rebates, GPs who reported income losses of $>50 \%$ decreased by $7.5 \% \quad(74.2 \%$ versus $66.7 \%$ ), while for specialists the decrease was $2 \%(82.5 \%$ vs $80.5 \%)$. Likewise, the proportion of GPs who reported income losses of $>75 \%$ decreased by $8.5 \%(39.8 \%$ vs $31.3 \%)$, in comparison to $4.8 \%$ (52\% vs $47.2 \%)$ for specialists.

Patient load and operating hours. There were 767 $(89.1 \%)$ and $449(52.1 \%)$ respondents who reported a $>50 \%$ and $>75 \%$ drop in patient loads, respectively (Table 1). The proportion of respondents from specialist and GP clinics who reported reduction in patient loads were similar (393 [99.7\%] vs 465 [99.6\%]). For operating hours, of the 629 owners or managers of clinics surveyed, $369(58.7 \%)$ reported reduced clinic operating hours, $39(6.2 \%)$ closed their clinics completely, $129(20.5 \%)$ cut operating hours by $>50 \%$, and the remaining $240(38.2 \%)$ cut operating hours by up to $50 \%$. More specialists' clinics reduced their operating hours compared to GP clinics (196 [71.3\%] vs $173[48.9 \%])$.

Employment practice. Of the 629 clinic owners/ managers, $53(8.4 \%)$ reported retrenching staff, with 43 and 42 respondents retrenching full-time and part-time staff, respectively. The mean number of full-time and part-time staff retrenched was 1.4 and 1.7, respectively.

A total of $74(11.8 \%)$ respondents instituted paycuts, with 43 and 42 respondents reducing the salary of full-time and part-time staff, respectively. The mean number of full-time and part-time staff receiving pay cuts was 4.8 and 2.7 , respectively. Of these staff, $52.7 \%$ had their pay cut by $<25 \%$, and $13.5 \%$ had their pay cut by $>50 \%$ (Table 2 ). 
Table 1. Impact of COVID-19 on income, patient load and clinic operating hours of private-sector physicians

\begin{tabular}{|c|c|c|c|c|c|c|}
\hline \multicolumn{7}{|c|}{ Number of doctors reporting changes in monthly incomes before and after government rebates } \\
\hline & \multicolumn{2}{|c|}{$\begin{array}{c}\text { GPs, no. (\%) } \\
\text { n=508 }\end{array}$} & \multicolumn{2}{|c|}{$\begin{array}{c}\text { Specialists, no. (\%) } \\
\text { n=394 }\end{array}$} & \multicolumn{2}{|c|}{$\begin{array}{l}\text { All, no. (\%) } \\
\mathrm{N}=902\end{array}$} \\
\hline & Before & After & Before & After & Before & After \\
\hline No income/laid off/closed completely & $36(7.1)$ & $35(6.9)$ & $11(2.8)$ & $9(2.3)$ & $47(5.2)$ & $44(4.9)$ \\
\hline Reduced by $>75 \%$ & $166(32.7)$ & $124(24.4)$ & $194(49.2)$ & $177(44.9)$ & $360(39.9)$ & $301(33.4)$ \\
\hline Total reduced by $>75 \%$ & $202(39.8)$ & $159(31.3)$ & $205(52.0)$ & $186(47.2)$ & $407(45.1)$ & $345(38.2)$ \\
\hline Reduced by $>50-75 \%$ & $175(34.4)$ & $180(35.4)$ & $120(30.5)$ & $131(33.2)$ & $295(32.7)$ & $311(34.5)$ \\
\hline Total reduced by $>\mathbf{5 0} \%$ & $377(74.2)$ & $339(66.7)$ & $325(82.5)$ & $317(80.5)$ & $702(77.8)$ & $656(72.7)$ \\
\hline Reduced by $>25-50 \%$ & $67(13.2)$ & $92(18.1)$ & $48(12.2)$ & $49(12.4)$ & $115(12.7)$ & $141(15.6)$ \\
\hline Reduced by $>10-24 \%$ & $22(4.3)$ & $32(6.3)$ & $12(3.0)$ & $14(3.6)$ & $34(3.8)$ & $46(5.1)$ \\
\hline Reduced by $<10 \%$ & $7(1.4)$ & $13(2.6)$ & $2(0.5)$ & $3(0.8)$ & $9(1.0)$ & $16(1.8)$ \\
\hline No impact & $34(6.7)$ & $30(5.9)$ & $7(1.8)$ & $11(2.8)$ & $41(4.5)$ & $41(4.5)$ \\
\hline Income increased & $1(0.2)$ & $2(0.4)$ & $0(0)$ & $0(0)$ & $1(0.1)$ & $2(0.2)$ \\
\hline \multicolumn{7}{|c|}{ Number of doctors reporting changes in patient load and clinic operating hours } \\
\hline & \multicolumn{3}{|c|}{ Patient load, ${ }^{\mathrm{a}}$ no. (\%) } & \multicolumn{3}{|c|}{ Operating hours, ${ }^{\mathrm{b}}$ no. (\%) } \\
\hline & $\begin{array}{c}\text { GPs } \\
\mathbf{n}=467\end{array}$ & $\begin{array}{c}\text { Specialists } \\
\mathrm{n}=394\end{array}$ & $\underset{\mathrm{N}=861}{\text { All }}$ & $\underset{\mathbf{n}=354}{\text { GPs }}$ & $\begin{array}{c}\text { Specialists } \\
n=275\end{array}$ & $\begin{array}{c}\text { All } \\
\mathrm{N}=\mathbf{6 2 9}\end{array}$ \\
\hline Closed completely & - & - & - & $31(8.8)$ & $8(2.9)$ & $39(6.2)$ \\
\hline Reduced by $>75 \%$ & $214(45.8)$ & $235(59.6)$ & $449(52.1)$ & $6(1.7)$ & $26(9.5)$ & $32(5.1)$ \\
\hline Reduced by $>50-75 \%$ & $204(43.7)$ & $114(28.9)$ & $318(36.9)$ & $12(3.4)$ & $46(16.7)$ & $58(9.2)$ \\
\hline Total reduced by $>50 \%$ & $418(89.5)$ & 349 (88.6) & $767(89.1)$ & $49(13.8)$ & $80(22.6)$ & $129(20.5)$ \\
\hline Reduced by $>25-50 \%$ & $43(9.2)$ & $36(9.1)$ & $79(9.2)$ & $35(9.9)$ & $63(22.9)$ & $98(15.6)$ \\
\hline Reduced by $>10-24 \%$ & $2(0.4)$ & $6(1.5)$ & $8(0.9)$ & \multirow{2}{*}{$89(25.1)$} & \multirow{2}{*}{$53(19.3)$} & \multirow{2}{*}{$142(22.6)$} \\
\hline Reduced by $<10 \%$ & $2(0.4)$ & $2(0.5)$ & $4(0.5)$ & & & \\
\hline Total reduced patient load/clinic operating hours & 465 (99.6) & $393(99.7)$ & $858(99.7)$ & $173(48.9)$ & $196(71.3)$ & $369(58.7)$ \\
\hline No impact & $2(0.4)$ & $1(0.3)$ & $3(0.3)$ & $181(51.1)$ & 79 (28.7) & $260(41.3)$ \\
\hline
\end{tabular}

a Excluding patient load of locum doctors

${ }^{\mathrm{b}}$ Only for those who are owners/managers of their own clinics

This study examined the impact of COVID-19 on income, patient load, operating hours, and employment practices of private-sector physicians. Our survey showed that more than three-quarters $(77.8 \%)$ of respondents suffered $>50 \%$ losses in monthly income. Government assistance ameliorated this loss, albeit to a limited degree. We posit that while the various schemes effectively lowered the fixed costs of practices (rental and workers' salaries), they could not fully address the impact of a drastic drop in patient load - a chief determinant of private-sector physician income.
COVID-19 appeared to affect private-sector specialists more than GPs, where specialist incomes are also more refractory to assistance schemes. There are several possible explanations. Firstly, anecdotal evidence suggests that many specialists see more foreign patients than their GP colleagues, thus they suffered from a larger fall in patient load due to stricter border controls. Secondly, the government assistance schemes were aimed at lowering the fixed costs of private-sector physicians, which comprised a higher percentage of a GP practice's revenue when compared to a specialist practice. 
Table 2. Number of doctors who implemented changes in employment practices

\begin{tabular}{|c|c|c|}
\hline Employment practice & $\mathrm{N}=629^{\mathrm{a}}$ & Number of staff affected, mean \\
\hline \multicolumn{3}{|c|}{ Staff retrenchment, no. (\%) } \\
\hline Did not retrench any staff & $576(91.6)$ & \\
\hline Retrenched staff & $53(8.4)$ & \\
\hline Retrenched full-time staff & $43(81.1)$ & 1.42 \\
\hline Retrenched part-time staff & $42(79.2)$ & 1.69 \\
\hline \multicolumn{3}{|c|}{ Staff pay cut, no. (\%) } \\
\hline Did not cut any staff pay & $555(88.2)$ & \\
\hline Instituted pay cuts & $74(11.8)$ & \\
\hline Cut the pay of full-time staff & $43(58.1)$ & 4.76 \\
\hline \multicolumn{3}{|l|}{ Amount of pay cut, mean } \\
\hline$<25 \%$ & $39(52.7)$ & \\
\hline $25-50 \%$ & $25(33.8)$ & \\
\hline$>50 \%$ & $10(13.5)$ & \\
\hline
\end{tabular}

a Only for those who are owners/managers of their own clinics

The decrease in workload was more pronounced than the decrease in income. This may be attributed to changes in patients' health-seeking behaviour in a pandemic. Patients may have self-medicated more during the current COVID-19 pandemic, leaving only severely ill patients to seek medical care, thereby attracting higher bill sizes. Changes in average bill sizes arising from the pandemic however, were not explored.

The current study has its limitations. As data were collected via a survey, it is subject to sampling bias. Physicians less comfortable with technology or with Internet access for example, may have been less forthcoming in responding to a survey. In addition, as our survey was conducted over 2 weeks with 31 May 2020 as the last day for responses to be submitted, we do not know if the private sector was affected over a longer period.

The healthcare landscape changes as the pandemic continues, reaching a longer-term COVID-19 equilibrium where medical service returns to business-as-usual. The incomes and practice patterns of private-sector physicians in the equilibrium warrant further investigation. Nonetheless, our study provides a crucial baseline for future studies tracking changes in physicians' practice over a longer period of the pandemic. A better understanding of the economic dynamics of the private healthcare sector may facilitate the implementation of policies best suited to support private practitioners, thereby enabling better healthcare continuity during and after the pandemic.

\section{REFERENCES}

1. Saw C, Lin J, Wong YJ. Impact of the COVID-19 pandemic on the Singapore economy. Available at: https://www.mti.gov.sg/-/media/ MTI/Resources/Economic-Survey-of-Singapore/2020/EconomicSurvey-of-Singapore-First-Quarter-2020/FA_1Q20.pdf. Accessed on 26 April 2021

2. Tan THY, Toh MPHS, Vasoo S, et al. Coronavirus disease 2019 (COVID-19): The Singapore experience. A review of the first eight months. Ann Acad Med Singap 2020;49:764-78.

Chiang Yin Wong, ${ }^{* 1}{ }_{F A M S}$, Mark Yu Zheng Wong, ${ }^{* 2}{ }_{B A}$, Tze Lee Tan, ${ }^{3}$ FCFPS, Yia Swam Tan, ${ }_{\text {FAMS }}$

\footnotetext{
Singapore Medical Association, Singapore

${ }^{2}$ School of Clinical Medicine, University of Cambridge, United Kingdom

${ }^{3}$ College of Family Physicians, Singapore

Correspondence: Dr Chiang Yin Wong, Singapore Medical Association, 2985 Jalan Bukit Merah, \#02-2C SMF Building, Singapore 159457.

Email: wcy@sma.org.sg

* Joint first authors
} 